\title{
16. Meaningful inefficiencies: Resisting the logic of technological efficiency in the design of civic systems
}

\author{
Eric Gordon and Stephen Walter
}

\begin{abstract}
The promise of smart cities is that Big Data and the Internet of Things will transform them into efficient, productive machines. But the smart city is a rather rational proposition where technological efficiency is the primary indicator of success. This chapter advocates a counterpoint to this emphasis on efficiency. Borrowing from game design, where players are provided with goals, and confronted with unnecessary obstacles that make their striving for that goal meaningful, the chapter suggest that 'meaningful inefficiencies' are necessary for making cities smart. When there is room for play in the systems with which we interact, there is opportunity for people to form relationships, build trust, care for one another, and make shared meaning, all of which comprise the foundation for resilient communities.
\end{abstract}

Keywords: Smart city, meaningful inefficiency, civic media, datafication, civic work

We are making government more user-friendly. - San Francisco's Mayor Ed Lee (Innovate SF 2013)

In the early 2000s, the City of Baltimore became the first large American city to organize all its major services under a single digital system and to utilize the collection and reporting of big data to increase efficiency in all aspects of government (O'Connell 2001). This program, called CitiStat, winner of the

Glas, R., S. Lammes, M. de Lange, J. Raessens, and I. de Vries, eds. 2019. The Playful Citizen. Civic Engagement in a Mediatized Culture. Amsterdam: Amsterdam University Press. DOI: $10.5117 / 9789462984523 / \mathrm{CH1} 6$ 
2004 Innovations in American Government Award, originally made use of existing, yet closed, data streams collected by sixteen agencies across the city. However, CitiStat would make two paradigm-shifting enhancements to the system. The first was the opening of a new, citizen-sourced data stream, a 311 citizen-reporting hotline-similar to 911 but for non-emergency calls — that linked directly to city service management; the second was in opening up the data to the public and using it as a 'civic communication tool.' This helped usher in a new age of e-reporting that soon spread to related data programs in New York, Chicago, and elsewhere. Now, as both data producers and data consumers, citizens ostensibly became partners to the government in making the basic functioning of the city more efficient (Ackerman 2004). This model of co-governance was met with much praise by tech-industry leaders. The IBM Center for the Business of Government sponsored a report praising the City of Baltimore for becoming "increasingly customer-friendly" as a result of its data-driven programs and for "the higher level of agency performance in delivering critical goods and services to citizens in the metropolitan area" (Henderson 2003, 6).

In the decade that followed, social networks such as Facebook and Twitter, publishing platforms from Patch to Tumblr, and mobile web-connected smart devices all worked to set new standards for how people communicate with each other. In April 2015, partly facilitated by these connective technologies, multiple videos captured by onlookers went viral showing an unarmed black man named Freddie Gray as he was dragged screaming into a police van by Baltimore police officers. Freddie Gray would later die due to injuries he sustained during his arrest.

Inspired by the videos captured by smartphones and amplified on social media, these same technologies were then utilized to coordinate widespread protests against police brutality across Baltimore, which would ostensibly 'shut the city down.' Certain city services were canceled, and a curfew was imposed. These events, and the often disquieting and extraordinary images, stories, and commentaries produced and shared from them, pushed the national conversation and media coverage about police brutality, mass incarceration, and urban inequality, to the center of attention. In a marked shift from other episodes of police brutality in the United States (e.g. in Ferguson, MO, and New York City), the state's attorney for the City of Baltimore, Marilyn Mosby, conducted a news conference where she both publicly ruled the death a homicide, charging the six officers involved, and, in unity with the protestors, openly acknowledged the "structural and systemic" racial issues present in policing, and the need for them to be broadly changed (Democracy Now! 2015). Although the decision was a result of many disparate 
current and historical factors, connective technologies played a part in the telling and reflection of the story. Without the capturing of video, without the amplification on social media, and without the tech-coordinated protests, this may have become another buried case of police brutality. Instead, it became a highly visual moment of reflection on the inequality inherent in Baltimore's systems of governance.

CitiStat in the early 2000 s and the protests in 2015 represent two starkly different cases of the use of technologies to 'efficiently' enhance or intervene in civic systems. With CitiStat, the notion of efficiency is born out of the technical and industrial sectors, defined by cost-effectiveness, speed, and market distribution. These efficiencies were intentionally designed into the system by a central design team. With the protests, efficiency is tied to what John Dewey (2011) has called 'civic efficiency,' or the ability to get things done with others, even if disruptive, messy, and unpredictable. In this case, existing technology was appropriated for an unexpected context, and civic efficiency emerged through its unique use by disparate actors. These two cases bring up important questions as to what efficiency means, for whom systems are efficient, and how efficiencies are designed into a civic technology. When the application of technology to civic life is celebrated purely for its expediency, transactionality, and instrumentality, then other uses and users are potentially sidelined. Civic technology is running on two parallel tracks - technological efficiency and civic efficiency — where an emerging technology sector is forming around streamlining government operations, and worldwide social movements are forming around unexpected uses of existing technology. While the latter track often produces dramatic images and stories that draw media attention and public conversation, the former track is becoming increasingly profitable and, we argue, dangerously overtaking the narrative of civic technology design and shifting the intentional mobilization of efficiency by designers, implementers, and funders to focus more on helping users of a technological system rather than citizens of a democracy.

The philosopher Hannah Arendt, writing in the 1950s in response to postwar industrialism in Europe and the United States, provides important insight into the logic of human systems, specifically the way tools and functions conceive of and mobilize their human users. Arendt (1998) argues that all human activity falls within three categories: labor, work, and action. Labor is a fundamental activity that maintains human life, an activity that caters to biological needs of production and consumption (the actual human effort that is mobilized toward work); work is an activity that contributes to the world that humans occupy (everything from building tools to thinking 
ideas); finally, action is the birth of a new political current in the world, a social means for change with no neatly predictable or prescribed ends.

The problem with many contemporary systems built purely with a focus on labor or work is that they too often view humans as interchangeable units, and imposed civic behavior replaces civic action. Arendt criticizes the rationalizing systems under which modern humans live for their tendency to elicit "from each of its members a certain kind of behavior, imposing innumerable and various rules, all of which tend to 'normalize' its members, to make them behave, to exclude spontaneous action or outstanding achievement" $(1998,41)$. Technology critic Evgeny Morozov echoes this in 2013 in the context of digital technology: "recasting all complex social situations either as neatly defined problems with definite, computable solutions or as transparent and self-evident processes that can be easily optimized-if only the right algorithm is in place!" is likely not even to achieve its predicted purpose, for the 'solutions' are often more tied to techno-utopian values than the realities of a messy, real world democracy (Morozov 2013, 5).

It is perhaps an irony then that modern web technologies might be the most effective medium ever to exist to facilitate action as Arendt defines it. Open, interconnected, mobile, complex, chaotic: the web not only provides potential for action through its ability to connect disparate people and to propagate ideas at a level never before realized, but it is also perfectly fitted to integrate into the contours of a democratic system-one complex pluralistic system intertwined with another. The job of civic systems can be to promote and curate this action while at the same time establishing stable "islands of predictability" through institutions, laws, and promises $(1998,244)$. When we invoke 'civic systems,' we mean any designed series of social interactions aimed at facilitating collective governance or action, be it a constituted system of national government aimed at sustaining integral institutions, a grassroots collective aimed at radically altering how voices are counted in a deliberative process, or an online forum dedicated to establishing and maintaining the rules and etiquette of a website. It is imperative that the designers of civic systems leverage web-based technology not for imposing behaviors, but for facilitating action.

In this chapter, we analyze the narrative of technological efficiency in the civic space. Contributing to what Elizabeth Losh calls the "Virtualpolitik," the narrative of technological efficiency has become part of everyday governance, impacting decisions made by the "managers of the nation state" $(2009,12)$. We seek to recognize where the narrative is challenged through alternative actions and designs. We introduce what we call meaningful inefficiencies as an emerging design paradigm for civic technology, which 
accommodates the possibility of messiness, disruption, and playing with rules and boundaries. Borrowing from the fields of game design and game studies, meaningful inefficiencies is a way of thinking about civic systems that are open to the affordances of play-what Roger Caillois refers to as an "occasion of pure waste" $(1958 / 2001,5)$-where users have the option to play within and with rules, not simply to play out prescribed tasks (Sutton-Smith 1997; Sicart 2014). While we argue for the value of play in the design and implementation of civic systems, we do not want to suggest that there is something inevitable in the playful (or ludic) paradigm (Raessens 2006, 2014; Walz 2010; Zimmerman 2015). Instead, we seek to understand play not as a paradigmatic shift, but as a characteristic of systems that has been overlooked in the current discourse surrounding technology and governance. Ultimately, in this chapter we present a call to action to understand civic technologies not simply in terms of what they do, but what people do with them. Designing for meaningful inefficiencies is a way of expanding technological civic systems to accommodate more than just the 'good user' of systems, but also the marginalized, the emergent, and the playful.

\section{User-friendliness}

While civic technology, or civic tech, in its current form is a new phenomenon, the insertion of technological efficiency into civic life is hardly new. Consider the design of cities. Twentieth-century urbanism has ushered in an understanding of cities as complex and rational systems (Mumford 2010) wherein the networks of building and roads could be conceptualized as a structure or language with which humans could interact (Alexander et al. 1977). But the end logic of the modernist city, the master-planned Brasilia or Robert Moses's rationalized sanitation of New York City, is what by today's standards would be called a dumb city, as they were systems designed and fixed in place with the premise of full automation without responsiveness to their human occupants. These mid-century modernist utopias were human systems designed for the abstracted and generic human user (Gordon 2010). More recently, discourses of the smart city, or the smarter city, have dominated contemporary city planning efforts around a simple premise - data generated through users of systems can inform the design and iteration of such systems (IBM 2012; Townsend 2013). In a big data environment, where mobile devices and sensors can capture movements, purchases and, social interactions, and where data from property, crime, and taxes are available and usable in aggregate, the promise of data-driven design 
is motivating change in urban systems and their governance (Caragliu, Del Bo, and Nijkamp 2009; Ratti and Townsend 2011). The individual is no longer the primary subject of governance; instead, governments have sought to become responsive to the aggregate data traces they leave behind (de Souza e Silva and Gordon 2013; Whitson 2015). Data sourced in aggregate, and the users that enable efficient data access, are the subjects directly addressed by government and organizations all within the celebrated framework of the 'user-friendly city.' This rhetoric was apparent in Baltimore's early CitiStat program, but questions about which customer was being served, and to whom the government was being friendly, arose with dramatic poignancy during the 2015 protests. The only people that get counted in aggregate, it would seem, are those who are good users of the systems provided.

Inequality and access have been insufficiently addressed in the context of 'smart' governance and city building, largely because it has been so heavily influenced by private sector-sponsored infrastructure projects, including IBM's Smarter Cities initiative, or contemporary master-planned city environments such as New Songdo City in South Korea. While the modernist representations of urbanism are apparent in these projects-skyscrapers, plazas, and highways - a central part of the infrastructure is the data scraped from citizens as they occupy these representations. Residents are conceived as users of systems, and most importantly, creators and users of data. Governing this smarter city, therefore, requires access, production, and analysis of data, and the conceptualization of the citizen as a producer of data within the confines of systems.

The city as system, much like any designed technical system, is designed for the user who uses the system well, or one who enters into the system in good faith to accomplish prescribed tasks. Users of technological systems often accommodate those systems in order to use them well (Lanier 2010) and the underlying code of systems becomes a kind of hidden legal framework that shapes social actions (Lessig 2006). For example, users learn how to navigate automated telephone lines in order to speak to a human being or learn how to use Facebook to reach their friends. Technological systems are always guiding and 'reskilling' their users as much as they are facilitating pre-mediated social actions (Latour 1988). Thus, technology that focuses only on designing more efficiency into civic life runs the risk of altering, without deliberation or oversight, the very constitution of what a citizen is and what they can or cannot do.

So when city government is framed as a user-friendly technological system, the characteristics of the 'good user' become the legible standin for the citizen. The concept of the 'good user' is based on normative 
structures of citizenship that situate the user solely within abstracted procedures, such as attending a meeting or voting or registering a complaint about a pothole. The users, conceived within the systems they use well, are necessarily articulated outside of any other modes of social integration such as place or cultural lineage that might otherwise compose political and civic identities (Habermas 2001), and determine patterns of inclusion or exclusion (Fraser 1990). Mechanisms of crafting citizenship such as formal or informal education (Callan 1997; Guttman 1999) and civic voice and activism (Manin 1997; Habermas 2001; Bennett 2008) are potentially sidelined in the minds of system architects to accommodate those already producing the appropriate data or those data-producing practices that can best accommodate new technological systems. The 'good user' is the rational, self-interested customer who demands efficient services toward prescribed ends. Similar to the concept of 'political consumerism,' or the buying or boycotting of products for political purposes (Stolle, Hooghe, and Micheletti 2005), the production or use of aggregate data is a form of consumerism that has direct impact on one's sense of engagement (or lack of same) in civic life (de Zúñiga, Copeland, and Bimber 2013).

\section{Hackability}

One of the first major instances with a city actively publicizing its ability to leverage private sector innovations occurred with CompStat in New York City. Originally developed for the NYPD in 1994, CompStat aimed to modernize the department through a "continuous improvement of performance" by employing "a variety of corporate strategies" to make its organizational structure more efficient (O'Connell 2001). At the core of CompStat is the requirement of routine data-based meetings where field commanders were mandated both to report and react to data generated from their precincts. This data resulted from a requirement that all precincts record a number of crime statistics on a neighborhood basis. The reaction to the data would trigger a street-by-street response, with the goal of rewarding commanders not by the number of arrests their staff made, but according to a drop in specific crime statistics.

Winner of the 1996 Innovations in American Government Award from the Harvard Kennedy School of Government, CompStat represents one of the first major city systems to fully embrace an emerging focus on the private sector: the collection and leveraging of big data. Soon, this datadriven approach to service management was adopted by other New York 
City departments-ParkStat for the Department of Parks and Recreation, TrafficStat for the traffic division, JobStat for the Human Resources Administration, and HealthStat for health insurance enrollment — and by other cities throughout the United States. It was Baltimore that fused all these various departments together in CitiStat.

E-government, Government 2.o, and open government are all terms used to describe the 'digital revolution' in government function and operation which have been influenced in no small way by CitiStat (Misuraca 2009; Ressler 2009; Poje 2011). Chun et al. (2010) identify several stages of e-government, ranging from the basic digitization of government records, to simple web-based transactions with available data, to more complex transactions such as paying taxes and fines. These early stages of e-government were focused solely on the efficiency of transactions at the municipal level, as we saw with the first 311 services. The current stage, they argue, is focused on interaction. It is about the quality of citizen interaction with government and the opportunities for collaborative decision-making through social media and open data. These three stages make clear the logical slippage between the digitization of records and citizen engagement. For e-government practitioners, these very different activities are placed under the umbrella of government efficiency and speak directly to the rhetorical promise of networked, web-based technologies for everyday governance.

This declarative position is in part fueled by the Obama administration's 2009 open government initiative, which established three principles for governing in the digital age: transparency, participation, and collaboration. According to the document, governments should make more data available to the public; they should make it easy to access basic services and information; and they should foster possibilities for interdepartmental and interagency collaboration. The initiative was directed to the federal government, but it has served as a justification for municipal government to devote resources to 'opening up.' As these principles of open government translate to the local level, they have maintained their focus on internal efficiency and appropriation of private sector rhetoric, but have also been refined to focus on direct service provision and citizen participation.

'Opening up' and empowering citizens has dominated the discourse of civic technology. But just as the civic tech community has celebrated these possibilities, they have also situated that openness within a language of control, specifically, in the discourse of technology, through the metaphor of hacking. According to Shannon Spanhake, San Francisco's Deputy Innovation Officer, "[c]ities are like living machines, and policy making in government is like writing the code that governs how a city operates. This 
city is the most complex machine I have ever had the opportunity to hack and it is what inspired my shift from the private sector to the public sector. \#helloworld" (Innovate SF 2013). Big data production and consumption has enabled the opening up of channels of communication, but at the same time, it has enabled designers of civic systems to control and hack the system. As a result of this conceptual framing, the citizen as a user of a hackable system, is disciplined through procedures of what philosopher Michel Foucault (1991) describes as governmentality, whereby under the promise of collaboration governments redouble their hold on power by dispersing it to the governed. In the actual operation of governments, this does not represent "a diminishment or a reduction of state sovereignty and planning capacities but a displacement from formal to informal techniques of government and the appearance of new actors on the scene of government (e.g. NGOs), that indicate fundamental transformations in statehood and a new relation between state and civil society actors" (Lemke 2002, 11). In this sense, government power can be maintained far more efficiently and pervasively not through external force, but by tacitly managing the possible forms of self-government and fields of action available to citizens (Söderström, Paasche, and Klauser, 2014). Hackability, according to the discourse of the smarter city, is often employed as a means of exerting control, as opposed to challenging it. It invokes an internal to government strategy that becomes a way of managing social difference, including race, class, and gender, by streamlining the good user into normative, technical activities.

\section{Civic labor and civic work}

The designers and proponents of civic technology too often articulate participation and openness within the framework of efficiency and control. This approach to governance is premised on defining a very specific user, one that is compelled to operate as an individual, presumably for personal benefit, but in the service of a system. Hannah Arendt's conceptions of labor and work provide useful frameworks for understanding this design paradigm.

When civic technologies are designed for labor, users are conceived as components of an efficient system, as laborers in achieving prescribed ends (i.e. 311 non-emergency systems). Systems designed to cultivate civic labor tend to be transactional, focusing on the curation of good habits and slipping into the background of everyday routine. Citizen mobile reporting apps and APIs such as Boston 311, NYC 311, or Chicago Works outsource 
the identification of problems directly to laborers. According to Arendt, to labor is "meant to be enslaved by necessity, and this enslavement was inherent in the conditions of human life" (1998, 83-84). Labor is the basic contribution to the maintenance of survival. No longer needing to attend extensively to biological survival, modern labor in post-industrial nations can be equated to the continual repetitive processes with which the status quo of any system is maintained. Not only does outsourcing labor to citizens increase efficiency and decrease costs for government if done correctly, but it also defines citizenship in transactional terms and as something done purely 'in service' to the basic continuation of the status quo and its existing power structures.

Systems designed with civic work in mind tend to consider the outcomes of labor and the use of those outcomes in the world. For example, public planning processes are typically framed as a collective effort toward designing a particular policy document through input and analysis. Contrary to simply using citizens as laborers for increasing the efficiency of civic life, civic designers deploy interventions that help to fabricate solutions and make citizens better users of existing civic systems. Whether traditional public information campaigns, education programs, mandatory requirements for participation, or web-enabled education and discussion apps, civic work aims to construct an artifice of efficient citizenship required by all in order to optimize the way civic systems are used. As opposed to using citizens to generate big data, here data is used to optimize citizens through systems of education or activity. For example, the attempt at crowd-sourcing a new constitution in Iceland after the protests in 2008-2009 is a good illustration of civic tech directed toward a specific work product. While the effort was ultimately rejected by Iceland's parliament in 2012, the process of using networked technology to steer collective labor toward specific ends is clearly represented in this example. However, the value of such efforts needs to be questioned given that the ratification of the new constitution, which was supported by 67 percent of voters, ended up being rejected because of only a few disenchanted MPs. Despite the 'opening up' through consolidating work efforts, the system remained hackable by its architects, essentially under the control of those already in power. Iceland, perhaps because of its highly connected (95 percent broadband use) and highly homogenous population, has continued to explore and support similar civic tech efforts such as Better Reykjavik, which is a mobile input system that has sourced since its start in 2010 over 1700 policy recommendations (with over 400 of them formally considered by the government). The example of Iceland demonstrates both the extraordinary affordances of streamlining civic 
work and the risk of it simply reifying existing power structures through governmentality.

Increasingly, practitioners in and out of government are looking to behavioral science for insights and for approaches to encouraging civic labor and work. In the UK, for example, the Behavioral Insights Team (sometimes called the 'Nudge Unit') was established in 2010 through the Prime Minister's Office to apply behavioral science to policy enforcement and service delivery. In the United States, the Obama administration established a similar office in 2014 called the Social and Behavioral Science Team (SBST). The notion of 'nudging' people as an approach to social policy was popularized by economist Richard Thaler and former Administrator of the White House Office of Information and Regulatory Affairs, Cass Sunstein. Nudging seeks to alter "people's behavior in a predictable way without forbidding any options or significantly changing their economic incentives" so that "consistent and unwavering people, in the private or public sector, can move groups and practices in their preferred direction" (Thaler and Sunstein 2009, 58). With the subtle coercion of citizens to govern their behaviors more efficiently through the internalization of mechanisms of control (as in governmentality), the citizen again takes on the qualities of a good user: predictably acting within a pre-defined system and pushed to act primarily in their own self-interest.

Many of these efforts have produced clear outcomes. For example, the benchmark program for the new SBST, in partnership with the United States Department of Education, sought to increase rates of federal loan repayment among those who had fallen behind. The team experimented with email communication to understand what form of address and frequency of email had the most impact on loan repayment. The results of the pilot demonstrated that sending emails to borrowers in delinquency for 90-180 days resulted in a statistically significant increase in repayment applications, with 6000 additional completed applications in the first month. These sorts of results hold significant promise for making government more efficient insofar as they seek to understand and iterate on the measurable behaviors of citizens. But they also reinscribe the notion of a citizen as a user of a system, as a consumer of services, while engaging in labor and work. In so doing, they bracket out the nuance, the unmeasurable, and the actions through which citizens construct meaning and form identities. By making civic systems more user-friendly, they ultimately make users friendlier to civic systems. 


\section{Civic action and meaningful inefficiencies}

Democracy does not always appear to be efficient. As the events in Baltimore demonstrate, anger and feelings of exclusion can lead to disruption of otherwise streamlined systems. But those same feelings, bolstered by social media and connective technologies, create what John Dewey (2011) calls 'civic efficiency,' or working with others to achieve public ends. "If democracy has a moral and ideal meaning," Dewey notes, "it is that a social return be demanded from all and that the opportunity for development of distinctive capacities be afforded all [...] the adoption of the narrower meaning of efficiency deprives it of its essential justification" (Ibid., 117). Dewey here is distinguishing 'technological efficiency' from the kind of 'civic efficiency' that makes social experiences valuable and educative. Both technological efficiency and civic efficiency are present in any democratic context, even as civic technologies push to produce and reproduce the former. The activities associated with Dewey's version of civic efficiency are born of Arendt's third category: action.

Democracy needs to allow for unpredictable, chaotic, novel civic action to occur, in which even "the smallest act in the most limited circumstance" and even "one deed, and sometimes one word, suffices to change every constellation" (Arendt 1998, 190). Action, as Arendt defines it, is the birth of a new political current, as small as a word or as large as a declaration, that reverberates through a human collective and interacts with everything and everyone, often imperceptibly. Allowing the freedom and providing a medium through which these waves can flow, enables the chaotic emergence of new ideas, new experiences, and new actions that a single individual, a group, or a data model could never achieve. The consequences are "boundless, because action, though it may proceed from nowhere, so to speak, acts into a medium where every reaction becomes a chain reaction and where every process is the cause of new processes" and that "no matter what its specific content, always establishes relationships and therefore has an inherent tendency to force open all limitations and cut across all boundaries" (Ibid.). An action can be set into motion by a single person, but it reverberates and grows in the social world where it takes on a character that transcends its initial design or intention through pluralistic, collective force. A system that permits action in Arendt's sense allows for collective contributions to a process or a cause to become more than the sum of its parts. From people in the Roxbury neighborhood of Boston commandeering the 311 system to focus the city's attention on blighted properties, to a simple hashtag, \#blacklivesmatter, created by a few activists after the acquittal of George 
Zimmerman in the wrongful death trial of African American teenager Trayvon Martin in Sanford, Florida - each action is a meaningful inefficiency with clear outcomes. One forced a city government to act on long ignored blighted properties and the other mobilized a global campaign to highlight racial injustices. While vastly different in scale, each is disrupting norms and challenging efficiencies in systems of governance.

In order to counteract technological efficiency as the dominant design value of civic systems, we suggest a concerted effort to design meaningful inefficiencies into human systems. Meaningful inefficiencies represent the design of systems for civic action, not behaviors. They can be civic tools, systems, or events, etc., that temporarily halt normal civic processes and create a delineated time or place in which play, disorder, messiness, and the ability to experiment and fail are safely utilized in productive - though not necessarily practical — ways. The results of these types of play can be increased civic learning, reflection, empathy, and increased awareness of civic systems and their effects - which citizens can then leverage in creating new forms of action in the normal processes of civic life.

A meaningful inefficiency, like Dewey's civic efficiency, ultimately aims to increase "neither more nor less than capacity to share in a give and take of experience. It covers all that makes one's own experience more worthwhile to others, and all that enables one to participate more richly in the worthwhile experiences of others" (Dewey 2011, 116). In the near dominance of technological efficiency in the design of civic systems today, meaningful inefficiency is necessarily an oppositional term, bringing to light the collapsing of the "range and accuracy [of a citizen's] perception of meanings" into machine-readable, hackable, and simplistic features (Ibid., $119)$.

We are not suggesting the design or cultivation of inefficiencies out of context. The fundamental requisite for a civic inefficiency to be 'meaningful' is that it is productively in tension with a new or existing efficiency. It would not necessarily be meaningful to create more inefficiencies where inefficiencies run rampant, such as in a situation where basic civic and social services do not exist. An inefficiency only becomes meaningful once it either provides a respite from efficiency, where citizens can share in a give and take of experience and increase their range and perception of meanings with each other, or when it provides a new view of the efficiency, where citizens are able to more fully understand how they are being shaped by the system-or how they might in turn be able to shape it. By doing so, this prompt allows for systems to make the uncertainties of variables fertile; the unexpectedness of outcomes revelatory; the opportunities for 
waste and the failure of resources and efforts constructive; the stakeholder complexities of interests and goals nourishing; and the deliberate misuses of the system constructive. Common to all meaningful inefficiencies, as we shall see below, is an element of play, or playfulness.

\section{Play}

Play is, in a sense, the mechanism of action in meaningful inefficiencies. Play can be defined as an activity in which the means are more valuable than the ends - that is, it is autotelic, it is done first and foremost for its own sake. Cultural historian Johan Huizinga writes: "in play there is something 'at play' which transcends the immediate needs of life and imparts meaning to the action. All play means something" $(1950,1)$. Thus, regardless of outcome - which certainly can be important-play itself is its own point. Players voluntarily enter into a system ostensibly in pursuit of some goal, but participation is not wholly dependent on the outcome of achieving that goal. For example, in a good game, players elect to play and the reward for playing is play itself. If one were to start a game of chess and beat their opponent in less than two minutes, the game would likely be unsatisfying for both the loser and the winner, because while the goal of winning provides direction, the goal of simply playing is not achieved. The uneven game of chess disallows the experience of play. The good user of chess is the one who beats her opponent in less than two minutes. The good player, however, is one that generates meaning from actions taken within the inefficiencies in the system - the circuitous paths one often takes to achieve victory in the face of unnecessary obstacles (Suits 2005).

While play is "an action accomplishing itself outside and above the necessities and seriousness of everyday life," at the same time it can, and often is, employed as a "helping-out of the action" of everyday life, beyond traditional play contexts (Huizinga 1950, 26, 15). Miguel Sicart suggests the term playfulness to apply to play in a "context that is not created or intended for play" $(2014,27)$. Fundamental to this act is the "appropriation of what should not be play." It is this act of appropriation, of bringing to bear on a serious situation in life, play-a mode of experience so fundamental to how we make meaning in the world as we grow, but so stamped out of adult life - that "we bring freedom to a context." Play is "personal, and playfulness is used to imbue the functional world with personal experience," while at the same time "revealing the seams of behaviors, technologies, or situations that we take for granted" (Ibid., 29). 
When playfulness is recognized and accommodated within civic systems, the result is a meaningful inefficiency, where the good user is propelled toward action, not just work and labor. In this sense, the notion of a user of a meaningfully inefficient civic system is not sufficient; when a system enables playfulness, either by design or accident, the user acts as a player with freedom to explore meaning well beyond the confines of the system in which they are operating. As such, the recognition of meaningful inefficiencies suggests the recognition of a playful citizen, not simply a good user.

The playful citizen, as a subject of civic systems, is more able to fully participate in the give and take of experience that Dewey declares so fundamental to democratic and personal growth. Acknowledging the playful citizen means recognizing that people actively play with and within systems, which necessitates being adaptable and responsive to unpredictable appropriations. This means that one should not, as internet scholar Yochai Benkler puts it, utilize "a straightforward, uncomplicated theory of human nature that reduces our actions as simple, predictable responses to punishments and incentives and helps us explain away confusing and even disturbing behaviorism," but that designers of civic technologies and citizens alike can learn from each other in a constant play of inventive meanings (Benkler 2011, 18).

"Vibrancy and efficiency may not be diametrically opposed," says Ethan Zuckerman, "but the forces are clearly in tension" $(2013,220)$. This tension can be productive; and, while challenging for designers, it is only through designing for the play of these and the other forces that facilitate and are moved by citizen action that it is possible to think about and build systems that "let our humanity find a fuller expression; systems that tap into a far greater promise and potential of human endeavor than we have generally allowed in the past" (Benkler 2011, 26). Instead of using new technological innovations to structure behavior so as to impose transactionality, efficiency, and predictability operating on that technology's own terms, it is possible to commission the chaos and emergent play of appropriations when new technology enters civic life, and to use citizen action to steer systems in new, unconventional directions.

\section{Meaningful inefficiencies: An (im)practical example}

The concept of disruptive design is nothing new. In the art world, examples abound in the twentieth century, from the Dadaists to the Situationists. Or more specifically in the realm of design, Carl DiSalvo's (2012) concept of adversarial design or Dunne and Raby's (2013) concept of speculative design 
each point to an interventionist practice in relation to dominant systems. What is unique about the concept of meaningful inefficiencies is its distinct focus on play and civic action taking, not only as an interventionist and deliberate act of design, but also as a characteristic that is inherent within existent systems. Our own experience in designing civic technologies is illustrative of the relevance of meaningful inefficiencies.

Motivated by a lack of community feedback systems in urban planning, in 2010 we were funded by the Knight Foundation to build a public dialog game. The project, in the end called Community PlanIt (Engagement Lab 2012), was an online social network meant to bring the public planning meeting online, increase the diversity of those who participated, and to scaffold the process with learning in order to enhance deliberation (Gordon and Baldwin-Philippi 2014). We were interested in making people more informed about the planning issues at hand, more capable of understanding the nuances and rules of a public planning process, and more congenial and empathetic toward other deliberators and decision makers. Following this, our goal, ultimately, was to create a new public planning process and to concurrently cultivate a good user of it. In other words, if we were to successfully introduce a new platform for public engagement, we would need to engage the public in using the platform well.

But, as happens in the early days of a design project, our focus lingered on all the bad users we seemed to be getting, and how we might be able to make them go away. Because of this, many of our early design iterations were about stamping out opportunities where bad users could unexpectedly appropriate our system and do something that we had not planned on. After some pilot tests in the Boston area, we set out to design a system that was more efficient, had more features, and eliminated uncertainty - not so much with the content people could put in to the system, but rather the way in which people could use the system. The value of the system, we suspected, was the layering of the social values of the internet (efficiency, archivability, searchability) onto the practical outcomes of most planning processes (conflict avoidance, ephemerality, and confusion).

However, as we deployed the game in two initial implementations (in Boston as part of a school policy planning process and in Detroit as part of an urban planning process), it was clear that the efficiencies so painstakingly built into the system were perhaps the least interesting (and least impactful) qualities of the game experience. While the efficiencies of online participation were an appealing selling point to funders and partners (each game attracted over a thousand players), in fact, the inefficiencies of gameplay created the greatest amount of interest. Ranging from humorously spamming 
the system with good-natured community event posts (which then created another tangent where participants deliberated about the unsaid rules of civil internet etiquette), to stepping away from the planning issues and talking about the game system itself, the role of youth in civic planning, what it meant to digitally engage with stakeholders or to imbue serious issues with a sense of fun, etc.- these actions were intentional means of appropriating the system to bring some other meaning to it. The best conversations and the most interesting insights did not occur from prompts by the designers, but rather the prompts or provocations created when users disrupted the normal use of the system and did something slightly different with it.

This sort of thing had occurred with virtually all the games or game-like systems we had created for civic engagement up to this point (Gordon and Manosevitch 2010; Gordon and Schirra 2012). But never was it clearer than in this experiment that perhaps our use of games was actually inadvertently doing something else that we were not taking into account; perhaps it was not the games themselves that offered the biggest value to these civic engagement processes, but rather something that emerged because of the very use of a game in this particular sociotechnical context. When tasked with organizing and finding a pattern to the most impactful moments for participants during the process, we realized it was not when the system was working fully, or during the moments when it was working but doing nothing more than facilitating simple transactional interactions such as liking comments or answering yes or no to a prompt; it also was not when a part of the system was simply broken, or was functionally pointless or redundant. The most impact, defined as opportunities to increase trust and efficacy, occurred in moments that were meaningfully inefficient—where either an existing inefficiency itself prompted the user to appropriate it to create some new meaning or action within the system, or when users were able to bring in some inefficiency of their own, and use that to temporarily disrupt the system and cause others to reflect upon what it is that is happening under their noses-how they have been designed and how they might be able to build off, or resist, such a design. If this observation was correct, and in fact community engagement matters most when the systems through which people engage are intentionally inefficient (in the technological sense), then our challenge became how to design for these meaningful inefficiencies. Indeed, in the years since Community PlanIt was first deployed, there has been a marked increase in the desire to see technologically efficient systems in processes of public engagement and civic life more generally. The use of games or game mechanics to achieve these ends was gaining popularity among marketing consultants and policy 
makers alike (McGonigal 2011; Zichermann and Cunningham 2011), even as it developed its very vocal critics in academia (Bogost 2015). But what made our project unique, and perhaps not as scalable as other solutions, was the inherent inefficiency in the system that compelled the user to explore alternative meanings. It was the experience of play, buried within our own gamified design and replete with messiness and ambiguity, that positioned us, inadvertently, in a discursive battle emerging within the conflation of technological efficiency and civic life.

Thus, when we set out to design a game to make planning more efficient, we found ourselves pushing up against the very affordances of games. Games are built to be inefficient as the player seeks to overcome unnecessary obstacles to reach the goal and to engage in the process of play for itself (Suits 2005). Civic tech, on the other hand, is steeped in the discourse of efficiency, with a laser focus on the instrumentality of activity. We became very aware of the tensions inherent in the system we designed-wanting to cultivate civic action through play, and at the same time appeal to funders and partners (foundations, municipal governments, and development organizations) to appease their sense of value through efficiency.

Applied games are often characterized as gamified systems (Deterding et al. 2011). In 2011, the term gamification saw a significant surge in popularity, most commonly applied to the use of game mechanics for specific behavior modifications, ranging from business to healthcare. The early location-based social network, Foursquare, used points and badges to motivate digital check-ins, and major corporations began using similar social incentives to increase productivity in the workforce. Gamified systems are widely considered to do three things: 1 ) they give users motivation to do something; 2) they give users the ability to complete the action; and 3) they give users a trigger or cue to complete the action (Laja 2012). Gamified systems, by this definition, are no different than the ideal systems conceived through the lens of civic tech. This is what makes our early design work with Community PlanIt so contradictory: it was a gamified system that promised some level of increased efficiency, yet was framed around the possibilities of play.

We began teasing out these distinctions very slowly. Our initial studies of Community PlanIt were focused on its capacity to increase efficiency in what we understood to be a dangerously inefficient system of urban planning (Gupta, Bouvier, and Gordon 2012). We sought to measure participation rates, reciprocity on the part of government stakeholders, and trust among users. It was not until later implementations and years of being steeped in discourses of gamification, that all the fissures and intentional ellipses 
that Community PlanIt brought to planning narratives demonstrated their value. The messy data of deliberation, the playful competition, and the creative storytelling were not simply artifacts of a system, but were central to its design.

The tensions that emerged in the implementation of Community PlanIt have been central to our evolved understanding of what it takes to recognize and design for civic action. Characteristics of play and playfulness were emergent within this system. While clearly also designed for labor and work, valued for the data produced by users, the system's incorporated elements of play, of encouraging exploration and discovery, were meaningful inefficiencies that came to define it. Or at least came to define our sense of what made it valuable. With the promise of the good user so persistent in civic tech discourse - a user self-disciplined through data production and consumption - the playful citizen became a necessary design prompt for us as a means of cultivating better, more humane systems that are scalable, meaningful, and allow for novel action to emerge.

\section{Conclusion}

The example of Community PlanIt represents our 'aha moment' in designing technologies that are meaningfully inefficient. We do not present it as a case study with particular observable outcomes, but as a study in process, wherein our expectations were subverted by the logics we had inadvertently designed into the system. Civic life is composed of actions, even if they are masked by the efficient presentation of labor and work. And civic technologies, properly conceived, should acknowledge and nurture the actions that are expressive and potentially transformative. We began this chapter by talking about the contrast present in the civic technology landscape of twenty-first-century Baltimore. On one hand, CitiStat represents a triumph of technological efficiency, where good users are effectively defined and governed through promises of 'user-friendliness' and 'hackability.' And on the other hand, the 2015 protests prompted by the unlawful death of Freddie Gray represent a triumph of civic efficiency led by those historically excluded from the category of 'good user.' The latter definition of efficiency is often realized in opposition to existent systems of governance, and for that reason, it is, in practice, a meaningful inefficiency. Civic technologies have the capacity to cultivate meaningful inefficiencies within a system that enables playful citizens to electively explore, experiment, resist, and reimagine the systems that govern their collective actions. 
We advocate for policymakers and civic technologists alike to incorporate meaningful inefficiencies into the design of civic systems in order to allow for emergent qualities and experiences beyond those prescribed to the good user. Civic systems should accommodate play through embracing: 1) uncertainties (of variables); 2) unexpectedness (of outcomes); 3) opportunities for waste and failure (of resources and efforts); 4) stakeholder complexity (of interests and goals); and 5) deliberate non-use or misuse (of the system). These qualities of play function as a kind of safety valve for the dominance of technological efficiency in civic design and encourage an evolution of democratic practices not absolutely contained by the rational means of their distribution.

We do not mean to suggest that technological efficiency lacks importance or that programs like CitiStat cannot contribute productively to civic life. The efficient delivery of basic services such as access to housing, policing, and healthcare, is essential. This sort of efficiency is a fundamental and important part of civic life and human activity, and certainly something not to be snuffed out. The danger is when technological efficiency goes unchecked, and the rigid systems are designed only for 'good users' - where the slightest unexpected use of the system by a user operating outside of the accepted norms is not accommodated or acknowledged. Ultimately, we suggest that designers, implementers, and funders of civic technologies take into account the existent qualities of labor, work, and action to more accurately pinpoint the function(s) of human activity they are meant to address. The future of civic technology needs to be critical of its ascending values of technological efficiency and not allow a technomentality to obscure relevant intervention points, contexts, and communities in need that may not play well with the rules of good use that have been articulated by the technology of the time. The basic question in civic tech today-how can we make civic life more efficient with technology - must be changed to, how can we use technology to make civic life more meaningful.

\section{Acknowledgments}

This chapter is based on a manuscript written in 2013, which since then has also been published in Gordon and Mihailidis (2016). 


\section{References}

Ackerman, J. 2004. Co-Governance for accountability: Beyond 'exit' and 'voice'. World Development 32 (3): 447-463.

Alexander, C., S. Ishikawa, M. Silverstein, M. Jacobson, I. Fiksdahl-King, and S. Angel. 1977. A pattern language: Towns, buildings, construction. Oxford: Oxford University Press.

Arendt, H. 1998. The human condition. Chicago, IL: University of Chicago Press.

Benkler, Y. 2011. The Penguin and the Leviathan: How cooperation triumphs over self-interest. New York: Crown Business.

Bennett, W. L. 2008. Changing citizenship in the digital age. In Civic life online: Learning how digital media can engage youth, ed. W. L. Bennett, 1-24. Cambridge, MA: The MIT Press.

Bogost, I. 2015. Why gamification is bullshit. In The gameful world: Approaches, issues, applications, eds. S. P. Walz and S. Deterding, 65-79. Cambridge, MA: The MIT Press.

Caillois, R. 1958/2001. Man, play, and games. Trans. M. Barash. Chicago, IL: University of Illinois Press.

Callan, E. 1997. Creating citizens. Oxford: Oxford University Press.

Caragliu, A., C. Del Bo, and P. Nijkamp. 20o9. Smart cities in Europe. Serie research memoranda 0048, VU University Amsterdam, Faculty of Economics, Business Administration and Econometrics. http://ideas.repec.org/p/ vua/wpaper/2009-48.html.

Chun, S. A., S. Shulman, R. Sandoval, and E. Hovy. 2010. Government 2.0: Making connections between citizens, data and government. Information Polity 15 (1, 2):1-9.

de Zúñiga, H. G., L. Copeland, and B. Bimber. 2013. Political consumerism: Civic engagement and the social media connection. New Media \& Society $16(3): 488-506$.

Democracy Now! 2015. WATCH: Baltimore prosecutor charges six police officers, calls Freddie Gray's death a "homicide". http://www.democracynow. org/blog/2015/5/1/watch_baltimore_prosecutor_charges_six_police.

Deterding, S., D. Dixon, R. Khaled, and L. Nacke. 2011. From game design elements to gamefulness: Defining "gamification". In Proceedings of the 15th international academic MindTrek conference: Envisioning future media environments, Tampere, September 28-30, 2011, 9-15. New York: ACM.

Dewey, J. 2011. Democracy and education. New York: Simon and Brown.

DiSalvo, C. 2012. Adversarial design. Cambridge, MA: The MIT Press.

Dunne, A., and F. Raby. 2013. Speculative everything. Cambridge, MA: The MIT Press. 
Engagement Lab. 2012. Community PlanIt. [browser]. Emerson College. Game.

Foucault, M. 1991. Governmentality. In The Foucault effect: Studies in governmentality, eds. G. Burchell, C. Gordon, and P. Miller, 87-104. Chicago, IL: University of Chicago Press.

Fraser, N. 1990. Rethinking the public sphere: A contribution to the critique of actually existing democracy. Social Text 25/26:56-8o.

Gordon, E. 2010. The urban spectator: American concept-cities from Kodak to Google. Hanover, NH: Dartmouth University Press.

Gordon, E., and J. Baldwin-Philippi. 2014. Playful civic learning: Enabling lateral trust and reflection in game-based public participation. International Journal of Communication 8:759-786.

Gordon, E., and E. Manosevitch. 2010. Augmented deliberation: Merging physical and virtual interaction to engage communities in urban planning. New Media and Society 13 (1): 75-95.

Gordon, E., and P. Mihailidis, eds. 2016. Civic media: Technology |Design | Practice. Cambridge, MA: The MIT Press.

Gordon, E., and S. Schirra. 2012. Playing with empathy: Digital role playing games in public meetings. In Proceedings of the 5 th international conference on communities and technologies, Brisbane, June 29-July 2, 2011, 179-185. ACM: New York.

Gupta, J., J. Bouvier, and E. Gordon. 2012. Exploring new modalities of public participation: An evaluation of digital gaming platforms on civic capacity and collective action in the Boston public school district. http:// placeofsocialmedia.com/projects-2.

Guttman, A. 1999. Democratic education. Princeton, NJ: Princeton University Press.

Habermas, J. 2001. The postnational constellation: Political essays. Trans. M. Pensky. Cambridge, MA: The MIT Press.

Henderson, L. 2003. The Baltimore CitiStat program: Performance and accountability. IBM Center for The Business of Government. http://www.businessofgovernment.org/report/baltimore-citistat -program-performance-and-accountability.

Huizinga, J. 1950. Homo ludens: A study of the play-element in culture. Boston, MA: Beacon Press.

IBM. 2012. Smarter, more competitive cities: Forward thinking cities are investing in insight. New York: IBM Corporation.

Innovate SF. 2013. The San Francisco Mayor's Office of Civic Innovation: A start-up called government-Our first year in retrospect. http://ofti.org/ wp-content/uploads/2013/05/2012Retrospective.pdf. 
Laja, P. 2012. How to Use Gamification for Better Business Results. Kissmetrics. http://blog.kissmetrics.com/gamification-for-better-results.

Lanier, J. 2010. You are not a gadget: A manifesto. New York: Thorndike Press.

Latour, B. 1988. Mixing humans and non-humans together: The sociology of a door closer. Social Problems 35 (3): 298-310.

Lemke, T. 2002. Foucault, governmentality, and critique. Rethinking Marxism 14 (3): $49-64$.

Lessig, L. 2006. Code: Version 2.o. New York: Basic Books.

Losh, E. 2009. Virtualpolitik: An electronic history of government mediamaking in a time of war, scandal, disaster, miscommunication, and mistakes. Cambridge, MA: The MIT Press.

Manin, B. 1997. Principles of representative government. New York: Cambridge University Press.

McGonigal, J. 2011. Reality is broken: Why games make us better and how they can change the world. New York: Penguin Press.

Misuraca, G. C. 2009. E-Government 2015: Exploring m-government scenarios, between ICT-driven experiments and citizen-centric implications. Technology Analysis \& Strategic Management 21 (3): 407-424.

Morozov, E. 2013. To save everything, click here: The folly of technological solutionism. New York: PublicAffairs.

Mumford, L. 2010. Technics and civilization. Chicago, IL: University of Chicago Press.

O'Connell, P. E. 2001. Using performance data for accountability: The New York City Police Department's CompStat model of police management. http://businessofgovernment.org/sites/default/files/CompStat.pdf.

Poje, J. 2011. Gov 2.0: Interaction, innovation and collaboration. Public Lawyer 19 (1): 2-11.

Raessens, J. 2006. Playful identities, or the ludification of culture. Games and Culture 1 (1): 52-57.

-. 2014. The ludification of culture. In Rethinking gamification, eds. M. Fuchs, S. Fizek, P. Ruffıno, and N. Schrape, 91-114. Lüneburg: meson press.

Ratti, C., and A. Townsend. 2011. Harnessing residents' electronic devices will yield truly smart cities. http://www.scientificamerican.com/article. cfm?id=the-social-nexus.

Ressler, S. 2009. The rise of Gov 2.0: From GovLoop to the White House. Public Manager 38 (3): 10-14.

Sicart, M. 2014. Play matters. Cambridge, MA: The MIT Press.

Söderström, O., T. Paasche, and F. Klauser. 2014. Smart cities as corporate storytelling. City 18 (3): 307-320. 
de Souza e Silva, A., and E. Gordon. 2013. The waning distinction between private and public: Net locality and the restructuring of space. In The international encyclopedia of media studies, ed. A. N. Valdivia, 195-214. Malden, MA: Wiley-Blackwell.

Stolle, D., M. Hooghe, and M. Micheletti. 2005. Politics in the supermarket: Political consumerism as a form of political participation. International Political Science Review 26 (3): 245-269.

Suits, B. 2005. The grasshopper: Games, life and utopia. Peterborough, Ont.: Broadview Press.

Sutton-Smith, B. 1997. The ambiguity of play. Cambridge, MA: Harvard University Press.

Thaler, R., and C. Sunstein. 2009. Nudge: Improving decisions about health, wealth, and happiness. New York: Penguin Books.

Townsend, A. 2013. Smart cities: Big data, civic hackers, and the quest for a new utopia. New York: W. W. Norton \& Company.

Walz, S. P. 2010. Toward a ludic architecture: The space of play and games. Pittsburgh, PA: ETC Press.

Whitson, J. 2015. Foucault's Fitbit: Governance and gamification. In The gameful world: Approaches, issues, applications, eds. S. P. Walz and S. Deterding, 339-358. Cambridge, MA: The MIT Press.

Zichermann, G., and C. Cunningham. 2011. Gamification by design: Implementing game mechanics in web and mobile apps. Seabastopol, CA: O'Reilly. Zimmerman, E. 2015. Manifesto for a ludic century. In The gameful world: Approaches, issues, applications, eds. S. P. Walz and S. Deterding, 19-22. Cambridge, MA: The MIT Press.

Zuckerman, E. 2013. Rewire: Digital cosmopolitanism in the age of connection. New York, NY: Norton W. W. \& Co. Inc.

\section{About the authors}

Eric Gordon is the founding director of the Engagement Lab and a Full Professor in the Department of Visual and Media Arts. He is particularly interested in the transformation of civic institutions, including government and journalism, in the wake of technological disruption, and the emerging tensions between technological efficiency in 'smart city' solutions and democratic governance. In addition to this research, Gordon works with cities and organizations around the world to design creative media approaches to public participation, using games, augmented reality, and virtual reality. He is the author of two books: Net locality: Why location matters in 
a networked world (Blackwell 2011, with Adriana de Souza e Silva) and The urban spectator: American concept cities from Kodak to Google (Dartmouth 2010), and the editor (with Paul Mihailidis) of Civic media:Technology|Design | Practice (The MIT Press 2016). His new book, tentatively titled Meaningful inefficiencies: Democracy and public value in the smart city, will be published by Oxford University Press.

Stephen Walter researches and designs civic media, technology, and spaces. At the Mayor's Office of New Urban Mechanics, he helps lead efforts around experiments in civic engagement, storytelling, technology, and research. Previously, Walter was the founding managing director of the Engagement Lab, an applied research lab for reimagining civic engagement in a digital era. He has conducted action research projects in places like Detroit, Boston, Philadelphia, Moldova, Zambia, Egypt, and Bhutan, and has worked at the International Red Cross/Red Crescent Climate Centre, the United Nations Development Program, the US Department of State, and the PBS television shows Frontline and Nova. His research also appears in the book Civic media: Technology $\mid$ Design $\mid$ Practice (The MIT Press 2016), and he is a research affiliate at the Berkman Klein Center for Internet and Society at Harvard. 